\title{
Epidemiology and Clinical Characteristics of Rapid Response Team Activations
}

\author{
Sei Won Kim , Hwa Young Lee ${ }^{2}$, Mi Ra Han ${ }^{3}$, Yong Suk Lee ${ }^{3}$, Eun Hyoung Kang ${ }^{3}$, \\ Eun Ju Jang ${ }^{3}$, Keum Sook Jeun ${ }^{3}$, and Seok Chan Kim ${ }^{4}$
}

\begin{abstract}
${ }^{1}$ Division of Pulmonology and Critical Care Medicine, Department of Internal Medicine, Daejeon St. Mary's Hospital, College of Medicine, The Catholic University of Korea, Daejeon; 2Division of Pulmonology and Critical Care Medicine, Department of Internal Medicine, Uijeongbu St. Mary's Hospital, College of Medicine, The Catholic University of Korea, Uijeongbu;

${ }^{3}$ St. Mary's Advanced Life Support Team, Department of Nursing, ${ }^{4}$ St. Mary's Advanced Life Support Team, Division of Pulmonology, Allergy and Critical Care Medicine, Department of Internal Medicine, Seoul St. Mary's Hospital, College of Medicine, The Catholic University of Korea, Seoul, Korea
\end{abstract}

Background: To ensure patient safety and improvements in the quality of hospital care, rapid response teams (RRTs) have been implemented in many countries, including Korea. The goal of an RRT is early identification and response to clinical deterioration in patients. However, there are differences in RRT systems among hospitals and limited data are available.

Methods: In Seoul St. Mary's Hospital, the St. Mary's Advanced Life Support Team was implemented in June 2013. We retrospectively reviewed the RRT activation records of 287 cases from June 2013 to December 2016.

Results: The median response time and median modified early warning score were 8.6 minutes (interquartile range, 5.6 to 11.6 minutes) and 5.0 points (interquartile range, 4.0 to 7.0 points), respectively. Residents (35.8\%) and nurses (59.1\%) were the main activators of the RRT. Interestingly, postoperative patients account for a large percentage of the RRT activation cases (69.3\%). The survival rate was $83.6 \%$ and survival was mainly associated with malignancy, Acute Physiology and Chronic Health Evaluation-II score, and the time from admission to RRT activation. RRT activation with screening showed a better outcome compared to activation via a phone call in terms of the intensive care unit admission rate and length of hospital stay after RRT activation.

Conclusions: Malignancy was the most important factor related to survival. In addition, RRT activation with patient screening showed a better outcome compared to activation via a phone call. Further studies are needed to determine the effective screening criteria and improve the quality of the RRT system.

Key Words: medical emergency team; rapid response system; screening; survival.

\section{Introduction}

Rapid response teams (RRTs) have been implemented to prevent serious adverse events, such as cardiac arrest, unexpected admission to the intensive care unit (ICU), and death [1]. According to several studies, serious adverse events are preceded for some hours by warning signs including abnormal vital signs, physiological instability, and an altered mental status [2-5]. Therefore, the goal of the RRT is early identification of a deteriorating patient showing warning signs, and

\author{
Received on March 29, 2017 Revised on April 27, 2017 Accepted on April 30, 2017 \\ Correspondence to: Seok Chan Kim, Division of Pulmonology, Allergy and Critical Care Medicine, Department of Internal Medicine, Seoul St. Mary's Hospital, College of \\ Medicine, The Catholic University of Korea, 222 Banpo-daero, Seocho-gu, Seoul 06591, Korea \\ Tel: +82-2-2258-6062, Fax: +82-2-2258-3589, E-mail: cmcksc@gmail.com \\ *No potential conflict of interest relevant to this article was reported.
}

(c) This is an Open Access article distributed under the terms of the Creative Commons Attribution Non-Commercial License (http://creativecommons.org/ licenses/by-nc/4.0/) which permits unrestricted non-commercial use, distribution, and reproduction in any medium, provided the original work is properly cited. Copyright (c) 2017 The Korean Society of Critical Care Medicine 


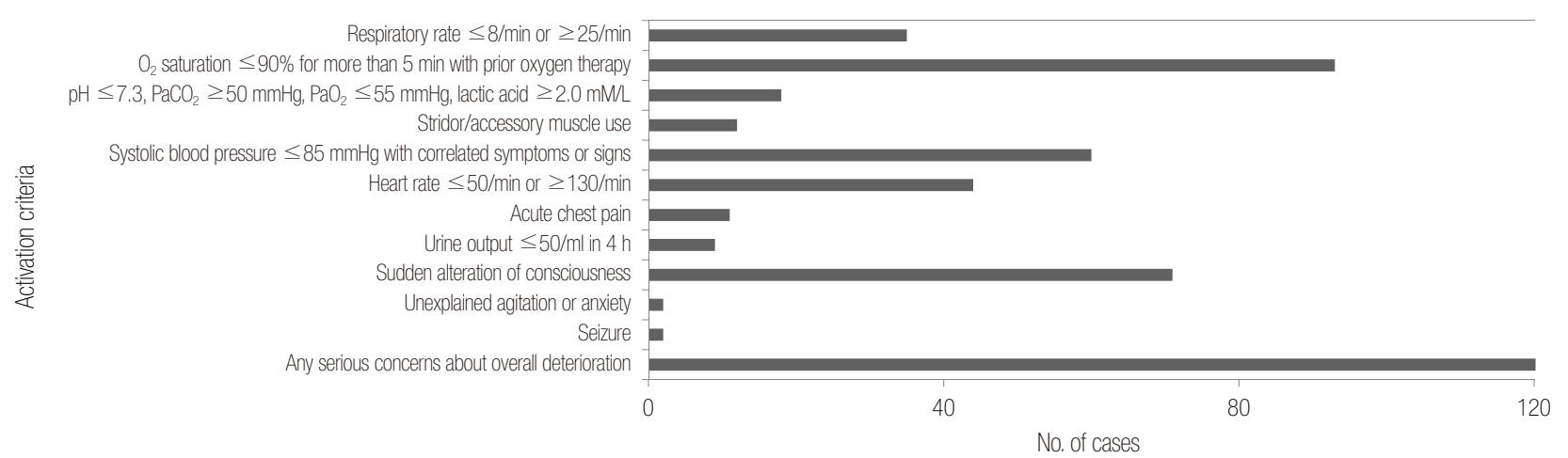

Figure 1. Reasons for rapid response team activation. There are 12 activation criteria, including a direct phone call for serious concerns about overall deterioration as detected by a physician, nurse, or caregivers at the bedside. Criteria can be duplicated.

an appropriate response before the occurrence of unintended adverse consequences [6].

To ensure patient safety and improve hospital quality of care, RRTs have been implemented in a number of countries. In the United States, the 100,000 lives campaign of the Institute for Healthcare Improvement recommended that hospitals implement RRTs as one of six strategies to reduce preventable in-hospital deaths [7]. Nowadays, most US hospitals have implemented an RRT in some form or other [8,9]. In Australia, an RRT system exists in two-thirds of all hospitals [10]. In Korea, RRTs have been mainly adopted in tertiary medical centers [11-13].

The clinical benefits of an RRT are still unclear [7,9]. Some studies showed favorable outcomes in terms of a decreased incidence of mortality from cardiac arrest and reduced ICU admission rate through the use of an RRT [14-17]. In contrast, other studies found no significant difference or had ambiguous results $[18,19]$. This discrepancy may be due to the heterogeneity of the study populations, and differences in RRT type, activation criteria, and quality of activation.

In this study, we retrospectively reviewed the RRT activation records of our institution to determine the clinical characteristics and predictors of survival of Korean patients who required an RRT activation.

\section{Materials and Methods}

\section{1) Subjects}

We retrospectively reviewed the RRT activation records of Seoul St. Mary's Hospital from June 2013 to December 2016. Seoul St. Mary's Hospital is a tertiary teaching hospital in Korea. With 22 upper floors, six basements, and 1,320 beds (including 119 beds in the ICU), it is the largest Korean hospital contained within a single building. Approximately 50,000 adult patients admitted to the hospital per year. The RRT of the hospital, called the St. Mary's Advanced Life Support Team (SALT), was implemented in June 2013 for hospital quality improvement. During the first 2 months of testing, the RRT targeted patients in the Department of Orthopedic Surgery. After successful testing, the range of RRT activations was gradually expanded to include other departments. Since June 2016, the RRT has covered all departments except those for pediatric patients. The RRT can be activated by both phone calls and a screening system. Approval was obtained from the institutional review board of Seoul St. Mary's Hospital. The requirement for informed consent was waived by the ethical review board.

\section{2) RRT description}

From June 2013 to May 2016, the duty hours of the RRT were from 8 AM to 10 PM on weekdays and from 8 AM to 4 PM on weekends and holidays. During this period, the RRT comprised three experienced RRT nurses, three 
to four pulmonologists (intensivists in charge of the medical ICU), two to three surgeons (intensivists in charge of the surgical ICU), and two to three residents training in the ICU. Intensivists were on duty from 8 AM to 5 PM on weekdays, while residents covered the RRT after 5 PM, and on weekends and holidays.

However, after May 2016, the RRT was changed to a 24-hour system and a greater number of medical staff (drawn from internal medicine, cardiothoracic surgery, general surgery, and neurosurgery) joined the RRT for overnight duty. The number of nurses in the RRT was also increased to nine.

\section{3) RRT activation and screening}

The criteria for RRT activation are shown in Figure 1. There are 12 activation criteria, including a direct phone call for any serious concerns about overall deterioration as detected by a physician, nurse, or caregivers at the bedside. Exclusion criteria were patients in the department of pediatrics, patients with a do not resuscitate status or in cardiopulmonary resuscitation. RRT activation was defined as the process when intensivists or residents arrive at the patient bedside and apply medical treatment, give consultation, or make decisions about ICU transfer. A portable multi-monitor and the enterprise pointof-care blood analysis system (Epoc; Alere, Waltham, MA, USA) were carried by the RRT at each activation. The Epoc system is a handheld, wireless solution that provides blood gas, electrolyte, and metabolite results at the patient's bedside within approximately 30 seconds of the introduction of a sample. Patients are also protected by an electronic medical record (EMR)-based screening system. If the clinical value in the EMR satisfies the RRT activation criteria, patients are automatically screened. The RRT charge nurse checks the condition of patients and recommends RRT activation to ward staff or nurses, as necessary. Postoperative and post-ICU monitoring are also in operation for particular departments. In 2016, 26,783 patients were screened (18,037 EMR-screened patients, 8,041 postoperative patients, and 707 post-ICU patients).

\section{4) Data collection}

Basic patient characteristics data, including sex, age, body mass index, admission route, department, admission ward, and past medical history (including malignancies), were collected from the EMR database. We also checked the status of the operation, number of postoperative days, activation method, response time, Acute Physiology and Chronic Health Evaluation-II (APACHE-II) score, modified early warning score (MEWS), position of activation, and RRT activation day, time, and reason. APACHE-II scores were collected from all patients with RRT activation regardless of ICU transfer, except the patients with RRT activation in 2013. Vital signs, and laboratory test and arterial blood gas analysis results at the time of RRT activation were also collected. Survival, length of hospital stay after RRT activation, and ICU transfer status (at the time of RRT activation and 24 hours after RRT activation) were examined as outcomes.

\section{5) Statistical analysis}

The mean and standard deviation were computed for normally distributed continuous variables, whereas medians and the interquartile range (IQR, 25th to 75th percentile) were used for non-normally distributed continuous data. Categorical data are described as numbers (\%). Student t-test was performed for normally distributed data, and the Mann-Whitney U-test was used for non-normally distributed data to compare clinical characteristics between subgroups. Categorical variables were compared using the chi-square and Fisher exact tests, as appropriate. Missing values were excluded from the analyses. Logistic regression analyses were performed to estimate the associations between survival and clinical characteristics. Clinical parameters with a P-value of 0.2 in the univariate logistic regression were included in the multivariate logistic regression. Odds ratios (ORs) and 95\% confidence intervals (CIs) were estimated. Statistical analyses were performed using R software ver. 3.1.1 (https://cran. r-project.org/). A P-value $<0.05$ was considered to be statistically significant. 

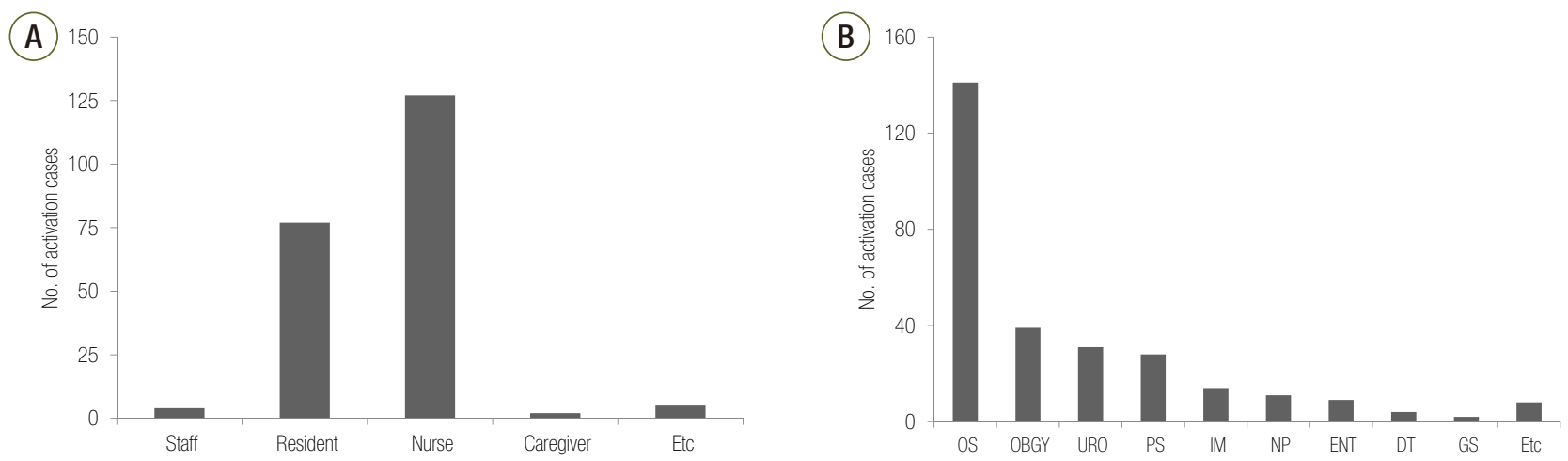

(C)

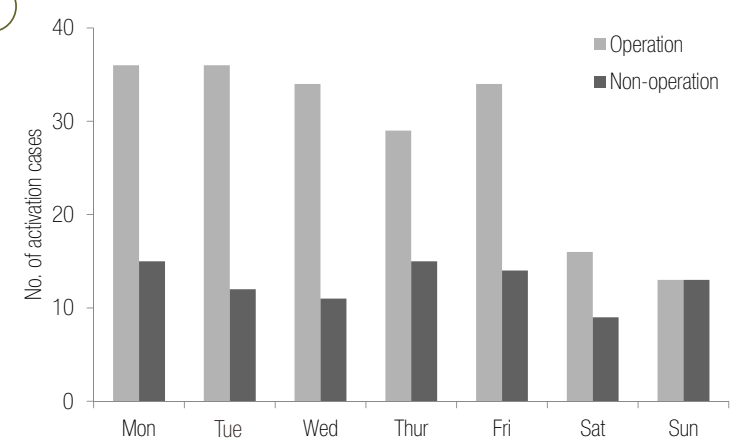

(D)

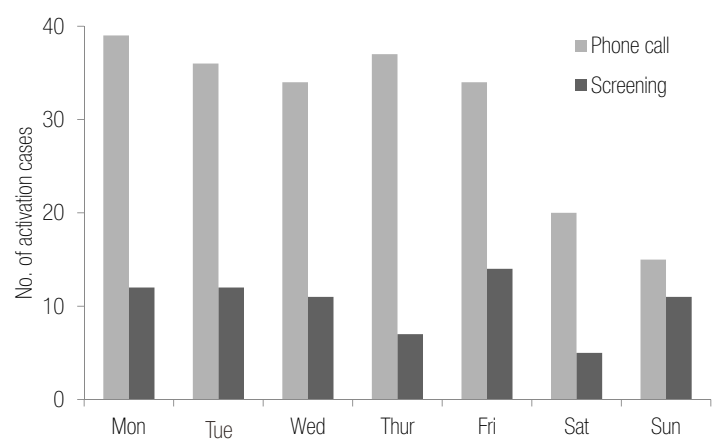

Figure 2. Epidemiology of rapid response team (RRT) activations. RRT activation according to (A) position, (B) department, (C) RRT activation by the specific day of the week according to the surgical status and (D) activation methods. OS: orthopedics; OBGY: obstetrics and gynecology; URO: urology; PS: plastic surgery; IM: internal medicine; NP: neuropsychiatry; ENT: otorhinolaryngology; DT: dentistry; GS: general surgery.

\section{Results}

\section{1) Epidemiology}

There were 1.4, 1.5, and 2.0 RRT activations/1,000 admissions in 2014, 2015, and 2016, respectively. Figure 1 shows the reasons for RRT activation. There are 12 activation criteria, and each criterion can be duplicated. The most frequent reason for activation was "serious concerns about overall deterioration." " $\mathrm{O}_{2}$ saturation $\leq 90 \%$ for more than 5 minutes with prior oxygen therapy," "sudden alteration of consciousness," and "systolic blood pressure $\leq 85 \mathrm{mmHg}$ with correlated symptoms or signs" were the most common reasons for RRT activation. RRT activation by phone call was mainly done by residents (77 cases, $35.8 \%$ ) and nurses (127 cases, 59.1\%) (Figure 2A). Orthopedics (49.1\%), obstetrics and gynecology (13.6\%), urology (10.8\%), and plastic surgery $(9.8 \%)$ were the most frequently activated departments (Figure 2B). We also analyzed the number of
RRT activations by the specific day of the week according to surgical status and activation method (Figure 2C and D). Although there was no significant group difference, the postoperative patients tended to be activated on weekdays. In contrast, the non-operation group showed only marginal variation over the week. Similarly, RRT activation by phone call showed a decreasing trend at the weekend. However, RRT activation with screening showed only marginal variation over the week.

\section{2) Clinical characteristics}

Table 1 lists the basic characteristics of the RRT activation cases. Of the 287 RRT activation cases, $43.2 \%$ were for male patients and their median age was 70.0 years (IQR, 58.0 to 78.0 years). The percentage of admissions via the outpatients department and emergency room was $56.1 \%$ and $43.9 \%$, respectively. The median body mass index, presence of malignancy, and a postoperative status 
Table 1. Basic characteristics of RRT activation

\begin{tabular}{|c|c|c|c|c|c|c|c|}
\hline \multirow[b]{2}{*}{ Characteristic } & \multirow[b]{2}{*}{ Total $(n=287)$} & \multicolumn{3}{|c|}{ Survival } & \multicolumn{3}{|c|}{ Activation method } \\
\hline & & $\begin{array}{l}\text { Survived } \\
(n=240)\end{array}$ & $\begin{array}{l}\text { Expired } \\
(\mathrm{n}=47)\end{array}$ & P-value & $\begin{array}{l}\text { Phone call } \\
(n=215)\end{array}$ & $\begin{array}{c}\text { Screening } \\
(n=72)\end{array}$ & P-value \\
\hline Male sex & $124(43.2)$ & $105(43.8)$ & $19(40.4)$ & 0.795 & $97(45.1)$ & $27(37.5)$ & 0.321 \\
\hline Age (yr) & $70.0(58.0-78.0)$ & $71.0(58.0-78.0)$ & $64.0(54.5-74.5)$ & 0.088 & $69.0(58.5-78.0)$ & $71.0(56.0-77.5)$ & 0.799 \\
\hline $\mathrm{BMI}\left(\mathrm{kg} / \mathrm{m}^{2}\right)$ & $23.0(20.1-25.8)$ & $23.0(20.1-25.8)$ & $22.9(20.5-24.9)$ & 0.784 & $23.0(20.0-25.8)$ & $22.9(20.6-25.7)$ & 0.495 \\
\hline Admission route & & & & 0.129 & & & 0.398 \\
\hline OPD & $160(56.1)$ & $129(54.0)$ & $31(67.4)$ & & $116(54.5)$ & $44(61.1)$ & \\
\hline ER & $125(43.9)$ & $110(46.0)$ & $15(32.6)$ & & $97(45.5)$ & $28(38.9)$ & \\
\hline Malignancy & $100(34.8)$ & $67(28.0)$ & $33(70.2)$ & $<0.001^{\mathrm{a}}$ & $76(35.5)$ & $24(33.3)$ & 0.847 \\
\hline Status of postoperation & $199(69.3)$ & $172(71.7)$ & $26(55.3)$ & $0.041^{\mathrm{a}}$ & $145(67.4)$ & $53(73.6)$ & 0.405 \\
\hline $\begin{array}{l}\text { Postoperation days } \\
\text { at RRT activation }^{b}\end{array}$ & $2.0(1.0-5.0)$ & $2.0(1.0-5.0)$ & $3.0(2.0-8.0)$ & $0.012^{\mathrm{a}}$ & $3.0(1.0-5.5)$ & $2.0(1.0-3.0)$ & 0.223 \\
\hline Response time (min) & $8.6(5.6-11.6)$ & $9.0(6.0-11.0)$ & $10.0(6.5-14.0)$ & 0.375 & $9.0(6.0-12.0)$ & $10.5(0.0-21.0)$ & 0.927 \\
\hline MEWS & $5.0(4.0-7.0)$ & $5.0(4.0-7.0)$ & $7.0(5.0-10.0)$ & $<0.001^{\mathrm{a}}$ & $5.0(4.0-8.0)$ & $5.0(4.0-7.0)$ & 0.656 \\
\hline APACHE-\| score ${ }^{c}$ & $14.0(10.0-18.0)$ & $13.0(9.0-18.0)$ & $16.5(13.0-23.0)$ & $<0.001^{\mathrm{a}}$ & $14.0(10.0-18.0)$ & $13.0(8.0-18.0)$ & 0.208 \\
\hline $\begin{array}{l}\text { RRT activation during } \\
\text { weekday except holidays }\end{array}$ & $229(79.8)$ & $195(81.2)$ & $34(72.3)$ & 0.233 & $175(81.4)$ & $54(75.0)$ & 0.317 \\
\hline $\begin{array}{l}\text { Days between admission } \\
\text { to RRT activation }\end{array}$ & $6.0(3.0-13.0)$ & $5.0(3.0-11.0)$ & $11.0(5.0-25.5)$ & $<0.001^{\mathrm{a}}$ & $6.0(3.0-13.0)$ & $5.0(2.0-13.5)$ & 0.622 \\
\hline
\end{tabular}

Values are presented as number (\%) or median (interquartile range).

RRT: rapid response team; BMl: body mass index; OPD: outpatient department; ER: emergency room; MEWS: modified early warning score; APACHE-II: Acute Physiology and Chronic Health Evaluation-II.

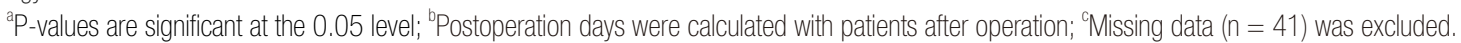

were $23.0 \mathrm{~kg} / \mathrm{m}^{2}$ (IQR, 20.1 to $25.8 \mathrm{~kg} / \mathrm{m}^{2}$ ), $34.8 \%$, and $69.3 \%$, respectively. For the postoperative patients, the RRT was activated on a median of 2.0 days (IQR, 1.0 to 5.0 days). The median response time, MEWS, and APACHEII score were 8.6 minutes (IQR, 5.6 to 11.6 minutes), 5.0 points (IQR, 4.0 to 7.0 points), and 14.0 points (IQR, 10.0 to 18.0 points), respectively. Approximately $80 \%$ of RRT activations occurred on weekdays, not including holidays, and the median number of days between admission and RRT activation was 6.0 days (IQR, 3.0 to 13.0 days). We also compared patients according to survival and activation method. The survival group showed a significantly lower rate of malignancy ( $\mathrm{P}<0.001)$, higher postoperative rate $(\mathrm{P}=0.041)$, lower MEWS $(\mathrm{P}<0.001)$, and lower APACHE-II score $(\mathrm{P}<0.001)$ compared to the expired group. In addition, the survival group showed a significantly lower number of days between admission and RRT activation $(\mathrm{P}<0.001)$. When only analyzing the postoper- ative patients, the survival group showed a lower number of postoperative days on which the RRT was activated ( $\mathrm{P}$ $=0.012$ ). Comparing the groups according to phone and screening activation methods, there was no significant difference in the basic characteristics.

\section{3) Outcome}

After RRT activation, about $30 \%$ of patients were moved to the ICU for further treatment (Table 2). The survival rate after RRT activation was $83.6 \%$, and $6.3 \%$ of patients required endotracheal intubation. The median hospital stay after RRT activation was 12.0 days (IQR, 6.0 to 25.5 days). The survival group showed a significantly lower intubation rate $(\mathrm{P}=0.019)$ and longer hospital stay after activation $(\mathrm{P}=0.008)$. Shorter hospital stay after activation in the expired group compared with survival group was due to early death after RRT activation. The phoneactivated group showed a significantly higher rate of ICU 
Table 2. Outcome after RRT activation

\begin{tabular}{|c|c|c|c|c|c|c|c|}
\hline \multirow[b]{2}{*}{ Characteristic } & \multirow[b]{2}{*}{ Total $(n=287)$} & \multicolumn{3}{|c|}{ Survival } & \multicolumn{3}{|c|}{ Activation method } \\
\hline & & $\begin{array}{l}\text { Survived } \\
(\mathrm{n}=240)\end{array}$ & $\begin{array}{l}\text { Expired } \\
(n=47)\end{array}$ & P-value & $\begin{array}{l}\text { Phone call } \\
(n=215)\end{array}$ & $\begin{array}{c}\text { Screening } \\
(\mathrm{n}=72)\end{array}$ & P-value \\
\hline At RRT activation & & & & 0.965 & & & 0.123 \\
\hline GW & $275(95.8)$ & $230(95.8)$ & $45(95.7)$ & & $203(94.4)$ & $72(100.0)$ & \\
\hline ICU & $7(2.4)$ & $6(2.5)$ & $1(2.1)$ & & $7(3.3)$ & 0 & \\
\hline Other & $5(1.7)$ & $4(1.6)$ & $1(2.1)$ & & $5(2.3)$ & 0 & \\
\hline After RRT activation & & & & 0.093 & & & $0.017^{\mathrm{a}}$ \\
\hline GW & $193(67.2)$ & $167(69.6)$ & $26(55.3)$ & & $135(62.8)$ & $58(80.6)$ & \\
\hline $\mathrm{ICU}$ & $91(31.7)$ & $70(29.2)$ & $21(44.7)$ & & 77 (35.8) & $14(19.4)$ & \\
\hline Other & $3(1.0)$ & $3(1.2)$ & 0 & & $3(1.4)$ & 0 & \\
\hline Intubation & 18 (6.3) & $11(4.6)$ & $7(14.9)$ & $0.019^{\mathrm{a}}$ & $17(7.9)$ & $1(1.4)$ & 0.090 \\
\hline Survival & $240(83.6)$ & - & - & - & 179 (83.3) & $61(84.7)$ & 0.915 \\
\hline $\begin{array}{c}\text { Hospital stay days } \\
\text { after activation }\end{array}$ & $12.0(6.0-25.5)$ & $12.5(7.0-26.5)$ & $7.0(1.0-22.0)$ & $0.008^{\mathrm{a}}$ & $13.0(7.0-31.0)$ & $11.0(5.5-16.0)$ & $0.022^{a}$ \\
\hline
\end{tabular}

Values are presented as number (\%) or median (interquartile range).

RRT: rapid response team; GW: general ward; ICU: intensive care unit.

${ }^{a} \mathrm{P}$-values are significant at the 0.05 level.

admissions $(\mathrm{P}=0.017)$ and longer hospital stay $(\mathrm{P}=0.022)$ after RRT activation compared to the screening group.

\section{4) Clinical parameters associated with survival}

On univariate logistic regression analysis, malignancy, a postoperative status, MEWS, APACHE-II score, number of days between admission and activation, and intubation were significantly associated with survival $(\mathrm{P}<0.001$, $\mathrm{P}=0.029, \mathrm{P}<0.001, \mathrm{P}<0.001, \mathrm{P}<0.001$, and $\mathrm{P}=0.012$, respectively) (Table 3). In multivariate logistic regression analysis, malignancy, APACHE-II score, and number of days between admission and activation were the clinical parameters found to be significantly associated with survival ( $\mathrm{P}$ $<0.001, \mathrm{P}=0.009$, and $\mathrm{P}=0.001$, respectively), with an $\mathrm{OR}$ of 7.47 ( $95 \%$ CI, 3.00 to 20.53 ), 1.10 (95\% CI, 1.03 to 1.19 ), and 1.04 (95\% CI, 1.02 to 1.07$)$, respectively.

\section{Discussion}

In this study, we retrospectively analyzed the RRT activation records of a single tertiary medical center. Over the course of 3.5 years, there were 287 RRT activations by both phone and screening. In our medical center, around $70 \%$ of RRT activations were for postoperative patients. After RRT activation, the survival rate of patients was $83.6 \%$, and approximately $30 \%$ of patients were moved to the ICU for further treatment. The presence of malignancy was the most important factor in survival. In addition, RRT activation with screening showed a favorable outcome compared with RRT activation by phone.

The afferent limb associated with RRT activation is one of the most important components to improve outcomes [13]. In our medical center, frequent promotion of RRT and education of the medical staff was performed along with RRT implementation. In addition, our RRT can be easily activated by a phone call to an RRT nurse. As a result, residents and nurses were the most frequent RRT activators, according to the data. Due to easy access to an RRT nurse, residents or nurses may feel less intimidated by making an RRT activation, and the percentage of early calls could thus increase [1]. Patient screening is also performed by an experienced RRT nurse for early detection and response. The current study showed that screening can lead to a favorable outcome, such as with respect to the ICU transfer rate and length of hospital stay after ac- 
Table 3. Clinical parameters associated with survival

\begin{tabular}{|c|c|c|c|c|}
\hline \multirow{2}{*}{ Variable } & \multicolumn{2}{|c|}{ Univariate analysis } & \multicolumn{2}{|c|}{ Multivariate analysis ${ }^{\mathrm{a}}$} \\
\hline & Odds ratio (95\% Cl) & P-value & Odds ratio $(95 \% \mathrm{Cl})$ & P-value \\
\hline Admission route & $1.76(0.92-3.51)$ & 0.096 & $1.06(0.46-2.49)$ & 0.889 \\
\hline Malignancy & $6.05(3.11-12.35)$ & $<0.001^{b}$ & $7.47(3.00-20.53)$ & $<0.001^{b}$ \\
\hline Status of postoperation & $0.49(0.26-0.93)$ & $0.029^{b}$ & $0.93(0.39-2.27)$ & 0.874 \\
\hline MEWS & $1.27(1.13-1.43)$ & $<0.001^{b}$ & $0.95(0.77-1.15)$ & 0.583 \\
\hline APACHE-II score & $1.11(1.05-1.17)$ & $<0.001^{b}$ & $1.10(1.03-1.19)$ & $0.009^{b}$ \\
\hline RRT activation during weekday except holiday & $1.66(0.79-3.33)$ & 0.167 & $0.91(0.31-2.44)$ & 0.862 \\
\hline Days between admission to RRT activation & $1.04(1.02-1.06)$ & $<0.001^{b}$ & $1.04(1.02-1.07)$ & $0.001^{b}$ \\
\hline Type of ward after activation & $1.65(0.90-2.98)$ & 0.102 & $1.96(0.79-4.79)$ & 0.143 \\
\hline Intubation & $3.64(1.27-9.82)$ & $0.012^{b}$ & $1.35(0.21-7.03)$ & 0.731 \\
\hline
\end{tabular}

Cl: confidence interval; MEWS: modified early warning score; APACHE-II: Acute Physiology and Chronic Health Evaluation-II; RRT: rapid response team.

${ }^{a}$ Clinical parameters which showed P-value, 0.2 at univariate logistic regression were included for multivariate logistic regression; ${ }^{b}$-values are significant at the 0.05 level.

tivation, compared with a phone call. Huh et al. [13] also demonstrated a better activation outcome by screening rather than by phone call. However, there were no significant differences in basic characteristics including MEWS and APACHE-II score between phone-activated group and screening group in our study. There are possibilities that patients were in different clinical severity with same MEWS or APACHE-II score. In addition, further studies with large population are needed to evaluate the clinical status more precisely.

In the efferent limb, our median response time, which is the time between RRT activation and the arrival of a physician, was 8.6 minutes. We did not include the type of intervention in this study due to a number of overlaps, inaccurate records, and difference in the quality. However, interventions were commonly for (1) managing intravenous fluid, (2) administering diuretics, (3) modifying antibiotics, (4) supplying oxygen and nebulizers, (5) ordering diagnostic studies, and (6) recommending consultation with other departments. About $30 \%$ of patients were moved to the ICU for further treatment.

Interestingly, about $70 \%$ of patients with an RRT activation were in postoperative care. In addition, departments related to surgery, such as orthopedics, obstetrics and gynecology, urology, and plastic surgery, were the main activators of the RRT in our medical center. From our results, patients in acute postoperative care tend to require a greater degree of RRT activation. In these surgical departments, a shortage of surgeons working on the general ward, and inexperience with medical emergencies, were the main reasons for an RRT call. However, we also experienced adverse outcomes, such as a decreased sense of responsibility, desensitization to emergencies for general ward physicians, and a heavy burden on RRT staff in cases where a high degree of intervention, rather than a quick second opinion, was expected [3,10]. In contrast, the proportion of internal medicine patients requiring RRT activation was lower than in other medical centers [11]. Some internists still questioned the effectiveness of the RRT and prefer to make decisions within their own subdivision. Although there were frequent screening detections from internal medicine patients, self-management was preferred in most cases rather than RRT activation. Greater discussion and education are needed to expand the range of RRT activities.

In an Australian study, the overall in-hospital mortality of RRT patients was about $25 \%$, compared with $15 \%$ in those not limited to medical therapy [10,20]. Another international prospective study of RRT showed a ward mortality rate of $11 \%$ [21]. In addition, age, national early 
warning score, and care limitations were significant predictors of mortality in a multivariable logistic regression. In our study, the overall mortality rate was $16.4 \%$. The presence of malignancy, APACHE-II score, and number of days between admission and RRT activation were significant factors in survival.

There were some limitations to this study. First, it used a retrospective, single center design. It is therefore difficult to generalize our results. However, our study provides more information on RRTs and could serve as a useful reference for modifying the RRT to fit the particular situation of each hospital. Second, although the RRT dose in our center is increasing annually, the RRT dose was lower than expected. A successful RRT system requires more than 25 calls per 1,000 admissions and a low call rate is known to be a key reason for failure [3,10,22]. To solve this problem, our RRT system was changed to a 24-hour system, and the range of RRT activations was expanded to all departments except pediatrics. As a result, the total number of RRT activation rose $57 \%$ compared with the same period a year earlier. Third, we categorized the patients with the presence of malignancy and status of postoperation. However, these classification may lead to selection bias due to diversity of type and severity. Finally, our institution's RRT records mostly concern postoperative patients. Further cooperation is needed with the subdivisions of the Department of Internal Medicine to improve the system.

In conclusion, this study delineates our experience of RRT implementation in a single tertiary medical center. Patient screening before a severe adverse event was an important factor in the outcome. The clinical parameters that were related to survival in this study can be used in RRT risk assessments. Further studies and efforts are needed to improve the quality of the current RRT system and achieve greater benefits.

\section{ORCID}

Sei Won Kim http://orcid.org/0000-0002-2798-421X Hwa Young Lee http://orcid.org/0000-0002-1582-2256

\section{References}

1. Devita MA, Bellomo R, Hillman K, Kellum J, Rotondi A, Teres D, et al. Findings of the first consensus conference on medical emergency teams. Crit Care Med 2006;34:2463-78.

2. Buist MD, Jarmolowski E, Burton PR, Bernard SA, Waxman BP, Anderson J. Recognising clinical instability in hospital patients before cardiac arrest or unplanned admission to intensive care: a pilot study in a tertiary-care hospital. Med J Aust 1999;171:22-5.

3. Jones DA, DeVita MA, Bellomo R. Rapid-response teams. N Engl J Med 2011;365:139-46.

4. Franklin C, Mathew J. Developing strategies to prevent inhospital cardiac arrest: analyzing responses of physicians and nurses in the hours before the event. Crit Care Med 1994;22:244-7.

5. Hillman KM, Bristow PJ, Chey T, Daffurn K, Jacques T, Norman SL, et al. Antecedents to hospital deaths. Intern Med J 2001;31:343-8.

6. Chen J, Ou L, Flabouris A, Hillman K, Bellomo R, Parr M. Impact of a standardized rapid response system on outcomes in a large healthcare jurisdiction. Resuscitation 2016;107:47-56.

7. Chan PS, Jain R, Nallmothu BK, Berg RA, Sasson C. Rapid response teams: a systematic review and metaanalysis. Arch Intern Med 2010;170:18-26.

8. Jung B, Daurat A, De Jong A, Chanques G, Mahul M, Monnin M, et al. Rapid response team and hospital mortality in hospitalized patients. Intensive Care Med 2016;42:494-504.

9. Salvatierra G, Bindler RC, Corbett C, Roll J, Daratha KB. Rapid response team implementation and inhospital mortality. Crit Care Med 2014;42:2001-6.

10. White K, Scott IA, Vaux A, Sullivan CM. Rapid response teams in adult hospitals: time for another look? Intern Med J 2015;45:1211-20.

11. Lee YJ, Lee DS, Min H, Choi YY, Lee EY, Song I, et al. Differences in the clinical characteristics of rapid response system activation in patients admitted to medical or surgical services. J Korean Med Sci 
2017;32:688-94.

12. Kwak HJ, Yun I, Kim SH, Sohn JW, Shin DH, Yoon $\mathrm{HJ}$, et al. The extended rapid response system: 1-year experience in a university hospital. J Korean Med Sci 2014;29:423-30.

13. Huh JW, Lim CM, Koh Y, Lee J, Jung YK, Seo HS, et al. Activation of a medical emergency team using an electronic medical recording-based screening system. Crit Care Med 2014;42:801-8.

14. Buist MD, Moore GE, Bernard SA, Waxman BP, Anderson JN, Nguyen TV. Effects of a medical emergency team on reduction of incidence of and mortality from unexpected cardiac arrests in hospital: preliminary study. BMJ 2002;324:387-90.

15. Dacey MJ, Mirza ER, Wilcox V, Doherty M, Mello $\mathrm{J}$, Boyer A, et al. The effect of a rapid response team on major clinical outcome measures in a community hospital. Crit Care Med 2007;35:2076-82.

16. Jones D, Bellomo R, Bates S, Warrillow S, Goldsmith D, Hart G, et al. Long term effect of a medical emergency team on cardiac arrests in a teaching hospital. Crit Care 2005;9:R808-15.

17. Sebat F, Musthafa AA, Johnson D, Kramer AA, Shoffner D, Eliason M, et al. Effect of a rapid re- sponse system for patients in shock on time to treatment and mortality during 5 years. Crit Care Med 2007;35:2568-75.

18. McGaughey J, Alderdice F, Fowler R, Kapila A, Mayhew A, Moutray M. Outreach and Early Warning Systems (EWS) for the prevention of intensive care admission and death of critically ill adult patients on general hospital wards. Cochrane Database Syst Rev 2007;(3):CD005529.

19. Hillman K, Chen J, Cretikos M, Bellomo R, Brown D, Doig $\mathrm{G}$, et al. Introduction of the medical emergency team (MET) system: a cluster-randomised controlled trial. Lancet 2005;365:2091-7.

20. Jones D. The epidemiology of adult rapid response team patients in Australia. Anaesth Intensive Care 2014;42:213-9.

21. Bannard-Smith J, Lighthall GK, Subbe CP, Durham L, Welch J, Bellomo R, et al. Clinical outcomes of patients seen by rapid response teams: a template for benchmarking international teams. Resuscitation 2016;107:7-12.

22. Jones D, Bellomo R, DeVita MA. Effectiveness of the medical emergency team: the importance of dose. Crit Care 2009;13:313. 